\title{
Towards A Global Anti-Diabetes Exercise Program
}

\author{
Akbar Nikkhah* \\ Chief Highly Distinguished Professor, Department of Animal Sciences, University of Zanjan, Iran \\ *Corresponding author: Akbar Nikkhah, Chief Highly Distinguished Professor, Department of Animal Sciences, Faculty of Agricultural Sciences, University of Zanjan, \\ Zanjan, Iran, National Elite Foundation, Tehran, Iran, Tel: +98-24-350-328-01; Fax: +98-24-350-332-02; E-mail: nikkhah@znu.ac.ir
}

Received date: June 25, 2015, Accepted date: June 26, 2015, Published date: June 30, 2015

Copyright: () 2015 Nikkhah A. This is an open-access article distributed under the terms of the Creative Commons Attribution License, which permits unrestricted use, distribution, and reproduction in any medium, provided the original author and source are credited.

\section{Editorial}

This article innovatively develops a global exercise program to feasibly prevent and ruin diabetes. Diabetes is a metabolic disease that results from a relatively prolonged adaptation of pancreatic and peripheral cells to abnormal glucose supply and uptake. This adverse bioprocess could be inherited from one generation to another and is fuelled by a meal-based daily impair of the balance that aims to minimize glucose overloads. As such, a global circadian exercise program is being developed to inhibit such a durable build-up in glucose over-supply and under-oxidation.

\section{Strategy Development: A Critical Analysis}

Type 2 diabetes is awkwardly on the rise in many parts of the globe, thus requiring feasible global strategies to minimize its risks of development. This more common type of diabetes is usually resulted from a relatively prolonged imbalance of glucose supply and utilization. This unhealthy bioprocess may increase diabetes risk via excessive adiposity and central obesity [1-3]. The favourable glucose use is augmented through oxidation that must be physically driven. Physical activity plays a significant role in creating a healthy balance between cellular supply and oxidation of glucose frequently and regularly.

The need for a regular and recurrent exercise program stems from the realm that glucose supply or indeed oversupply to the cells occurs usually regularly and frequently [4-6]. Because of the circadian nature of food intake and the consumption of only few large daily meals, any efficacious exercise program must involve adequate physical activity on a daily or at the very least on an every-other-day basis [7-9]. Even the daily exercise must be conducted adequately intense to greatly induce increased heart work and significant sweating. The latter helps improve waste management and reduce cellular exposure to oncogenic factors and peroxidation. Due to the dramatically reduced physical work in the modern age, glucose oversupply frequently occurs. In addition, increased brain work does not sufficiently compensate for the decreased physical activity. As a result, obesity of varying degrees often develops, a serious problem that today's world severely encounters $[10,11]$

An erroneous public perception exists that believes any daily exercise (e.g., even prolonged walking) is adequately effective in preventing obesity and removing the chance of diabetes. But, the fact is that light exercise not causing prolonged sweating and high heart rate does not lead to oxidizing adequate substrates. What often exacerbates the problem is post-exercise overeating that despite the increased nutrient burning, elevates total daily nutrient intake. This positive energy balance unnoticeably and gradually leads to overweightness. As a rule of thumb, exercise if not conducted intensely and knowledgeably, does not prevent positive energy balance and may even considerably increase risks of energy oversupply, adiposity and diabetes.

A pragmatic global recommendation to ensure a healthy lifestyle would be consuming multiple small food meals (e.g., 5-6 meals daily) and daily regular exercise of intense physical work. Once or even twice a week exercise would never be completely successful in improving human health in today's modernized, physically passive, and stressful life.

\section{Conclusion}

This article raised serious concerns on adequacy of long-interval exercise programs in minimizing diabetes. Careless and infrequent exercise does not prevent diabetes and may even increase nutrient oversupply and daily energy balance. This fuels central adiposity that gradually and unnoticeably causes obesity, making the body more prone to diabetes. Exercise must be exercised intensely and realistically no less than three times weekly to be effective against diabetes. Physical work must be accompanied by limit-eating to inhibit hungerdriven overeating.

\section{Acknowledgment}

Thanks to the Ministry of Science Research and Technology, National Elite Foundation, and University of Zanjan for supporting the author's global initiatives and pragmatic programs of optimizing science edification in the new millennium.

\section{References}

1. Nikkhah A (2015) Discovering the Right Time to Take Food to Smash Diabetes. J Diabetes Res Ther Volume 1: 102.

2. Nikkhah A (2014) Timing of Eating to Eradicate Diabetes: A Feasible Prescription. J Diabetes Metab 5: e117.

3. Nikkhah A (2014) Eating timing and diabetes. Diabetol Vasc Dis Res 2: 1.

4. Nikkhah A (2015) Timely Open-Air Exercise Postpartum for Healthy Maternal Recovery. J Bioprocess Biotech.

5. Nikkhah A (2015) Circadian Fitting of Exercise and Eating Patterns: The Secret of Healthy Life. J Bioprocess Biotech 5: e129.

6. Nikkhah A (2015) Harmonizing Eating and Exercise Circadian Rhythms for Optimal Glucose-Insulin and Vascular Physiology. Int J Diabetol Vasc Dis Res 3: 87-88.

7. Nikkhah A (2015) Breast Health Progress through Exercise-Driven Lactation: A Pragmatic Bioprocess to Prevent Cancer. J Bioprocess Biotech 5: e127.

8. Nikkhah A (2015) Circadian Timing and Regularity of Physical Activity: A Novel Bioprocess to Prevent Devastating Modern Diseases. J Bioprocess Biotech 5: e131. 
Citation: Nikkhah A (2015) Towards A Global Anti-Diabetes Exercise Program. J Bioprocess Biotech 5: e135. doi:10.4172/2155-9821.1000e135

Page 2 of 2

9. Nikkhah A (2015) Secure Weight Management via Fitting Circadian Patterns of Physical Activity, Resting and Eating. Adv Weigh Manag Obes Cont 2: 23

10. Nikkhah A (2014) Circadian Synchrony of Insulin and Intake Patterns Towards a Rational Anti-Obesity Theory. Endocrinol Metab Synd 3: e122.
11. Nikkhah A (2014) When to Eat to Beat Obesity and Diabetes? J Diabetes Metab 5: e115. 